\title{
Kunci identifikasi lalat buah (Diptera: Tephritidae) di Kabupaten Bogor dan sekitarnya
}

\author{
Identification key of fruit flies (Diptera: Tephritidae) \\ in Bogor District and its surounding area
}

\author{
Anik Larasati, Purnama Hidayat*, Damayanti Buchori \\ Departemen Proteksi Tanaman, Institut Pertanian Bogor \\ Jalan Kamper, Kampus IPB Dramaga, Bogor 16680
}

(diterima April 2013, disetujui Maret 2016)

\begin{abstract}
ABSTRAK
Kunci identifikasi lalat buah memberikan informasi taksonomi yang berkaitan dengan identifikasi spesies lalat buah berdasarkan karakteryang terdapat pada imago lalat buah. Kunci ini dibuat berdasarkan koleksi lalat buah dari Kabupaten Bogor dan sekitarnya. Spesies lalat buah yang dideskripsikan dalam kunci identifikasi terdiri dari 18 spesies lalat buah yang termasuk ke dalam 2 genus dan 4 subgenus, yaitu Bactrocera (Bactrocera) albistrigata de meijere, Bactrocera (Bactrocera) carambolae Drew \& Hancock, Bactrocera (Bactrocera) caudata Fabricus, Bactrocera (Bactrocera) latifrons White \& Liquido, Bactrocera (Bactrocera) limbifera Bezzi, Bactrocera (Bactrocera) melastomatos Drew \& Hancock, Bactrocera (Bactrocera) moluccensis Perkins, Bactrocera (Bactrocera) occipitalis Drew \& Hancock, Bactrocera (Bactrocera) papayae Drew \& Hancock, Bactrocera (Bactrocera) tau Walker, Bactrocera (Bactrocera) umbrosa Fabricius, Bactrocera (Bactrocera) usitata Drew \& Hancock, Bactrocera (Bactrocera) verbascifoliae Drew \& Hancock, Bactrocera (Bactrocera) vulta Hardy, Bactrocera (Bulladacus) mcgregori Bezzi, Bactrocera (Zeugodacus) calumniata Hardy, Bactrocera (Bactrocera) cucurbitae Coquillet, Dacus (Callantra) longicornis Wiedemann. Penyusunan kunci identifikasi dilakukan dengan membuat matriks karakter, dengan membandingkan beberapa karakter, seperti face spot, lateral postsutural vittae, warna tungkai, lebar dan sempitnya pita kostal, medial longitudinal band, serta lateral margin dari terga III hingga V.
\end{abstract}

Kata kunci: Bactrocera, Dacus, hama buah, karakter morfologi, kunci identifikasi

\begin{abstract}
Identification key was developed for 18 species of fruit flies (Bactocera spp.) found in Bogor district. Morphological characters were used as background information for key development: 2 genus and 4 subgenus were identified in the process. Fruit fly species in this identification was Bactrocera (Bactrocera) albistrigata de meijere, Bactrocera (Bactrocera) carambolae Drew \& Hancock, Bactrocera (Bactrocera) caudata Fabricus, Bactrocera (Bactrocera) latifrons White \& Liquido, Bactrocera (Bactrocera) limbifera Bezzi, Bactrocera (Bactrocera) melastomatos Drew \& Hancock, Bactrocera (Bactrocera) moluccensis Perkins, Bactrocera (Bactrocera) occipitalis Drew \& Hancock, Bactrocera (Bactrocera) papayae Drew \& Hancock, Bactrocera (Bactrocera) tau Walker, Bactrocera (Bactrocera) umbrosa Fabricius, Bactrocera (Bactrocera) usitata Drew \& Hancock, Bactrocera (Bactrocera) verbascifoliae Drew \& Hancock, Bactrocera (Bactrocera) vulta Hardy, Bactrocera (Bulladacus) mcgregori Bezzi, Bactrocera (Zeugodacus) calumniata Hardy, Bactrocera (Bactrocera) cucurbitae Coquillet, Dacus (Callantra) longicornis Wiedemann. Preparation of identification keys were done by created a matrix of characters, through comparing several characters such as face spot, lateral postsutural vittae, the color of the legs, wide and narrow costal band, medial longitudinal band, as well as the lateral margin of terga III to V.
\end{abstract}

Key words: Bactrocera, Dacus, fruit pest, identification key, morphological character

\footnotetext{
* Penulis korespondensi: Purnama Hidayat. Departemen Proteksi Tanaman, Fakultas Pertanian, Institut Pertanian Bogor Jalan Kamper, Kampus IPB Dramaga, Bogor 16680, Tel/Faks: 0251-8629364, Email: purnamahidayat@gmail.com
} 


\section{PENDAHULUAN}

Lalat buah dari kelompok famili Tephritidae, Ordo Diptera memiliki arti penting dalam budi daya tanaman buah-buahan dan sayuran. Secara khusus, lalat buah dapat menyebabkan kerusakan secara kualitatif dan kuantitatif serta berpotensi menyebabkan penurunan produksi buah (Siwi et al. 2006). Tingkat kerusakan yang ditimbulkan oleh lalat buah pada buah dan sayuran yang terserang dapat mencapai 90\% (Pusat Teknik dan Metoda Karantina Hewan dan Tumbuhan 2004).

Lalat buah dari kelompok Tephritidae termasuk ke dalam kelompok serangga kosmopolitan yang tersebar di berbagai wilayah tropis dan subtropis (White \& Harris 1992). Indonesia merupakan salah satu negara tropis yang memiliki keanekaragaman lalat buah yang cukup tinggi. Berdasarkan survei yang dilakukan oleh AQIS (2008), dijumpai 63 spesies lalat buah yang terdapat di Indonesia. Namun, hanya 10 spesies lalat buah yang diketahui berperan sebagai hama potensial bagi tanaman budi daya.

Salah satu wilayah Indonesia yang diketahui memiliki keanekaragaman inang lalat buah adalah Kabupaten Bogor serta beberapa wilayah lainnya di Kabupaten Depok, Bekasi, dan Cianjur. Terdapat 18 spesies lalat buah yang ditemukan melalui pemeliharaan inang berupa buah yang terinfestasi dan pemasangan perangkap yang diletakkan di Kabupaten Bogor dan sekitarnya (Larasati 2012).

Kunci identifikasi lalat buah tidak hanya memberikan informasi terkait bidang taksonomi, namun juga turut memberikan manfaat dalam program pengelolaan hama lalat buah (Prabhakar et al. 2012). Selain itu, adanya kunci identifikasi lalat buah juga memberikan manfaat dalam mengenali spesies lalat buah yang berpotensi sebagai hama tanaman komersial maupun hama tanaman nonkomersial di suatu wilayah. Kunci identifikasi yang baik adalah yang mudah untuk digunakan serta diaplikasikan dalam proses identifikasi lalat buah (Faria et al. 2014). Tujuan dari pembuatan kunci lalat buah di Kabupaten Bogor dan area sekitarnya adalah untuk memberikan informasi taksonomi serta membantu dalam identifikasi lalat buah yang terdapat di Kabupaten Bogor dan sekitarnya.

\section{BAHAN DAN METODE}

\section{Koleksi lalat buah}

Seluruh spesimen lalat buah yang dideskripsikan dan digunakan untuk membuat kunci identifikasi disimpan dalam bentuk koleksi kering yang didapatkan melalui metode pemeliharaan inang dan pemasangan perangkap (Larasati 2013) dan tersimpan di Museum Serangga, Laboratorium Taksonomi Serangga, Departemen Proteksi Tanaman, Institut Pertanian Bogor (IPB).

\section{Penyusunan kunci identifikasi}

Pembuatan kunci identifikasi lalat buah diawali dengan membuat matriks karakter dengan format tabulasi dari seluruh spesies lalat buah yang ditemukan. Karakter yang digunakan pada kunci identifikasi disitir dari berbagai karakter morfologi yang terdapat pada kunci identifikasi lalat buah yang dikeluarkan oleh AQIS (2008) serta CABI (2007). Informasi mengenai sejarah perubahan nama spesies dan authornya, serta sebaran spesies lalat buah disitir dari buku Tropical Fruit Flies Drew \& Romig (2013) dan AQIS (2008). Karakter yang berbeda pada satu bagian morfologi lalat buah digunakan untuk membuat kaplet dikotomus. Kaplet dikotomus merupakan sepasang karakter yang berbeda yang kemudian dipilih oleh pengguna/ identifikator dengan mencocokkan karakter yang sama/sesuai dengan karakter spesimen yang sedang diidentifikasi. Karakter yang berbeda pada lalat buah dapat ditemukan pada lateral postsutural vittae, warna skutum, spot pada wajah, venasi pada sayap, warna tungkai, tipe aculeus pada ovipositor, panjang ovipositor, warna dan pola yang terdapat pada abdomen (Gambar 1). Kaplet dikotomus yang terdapat pada kunci identifikasi digunakan untuk membandingkan dua karakter yang berbeda. Karakter morfologi yang bersifat spesifik digunakan untuk merujuk masingmasing spesies lalat buah. 


\section{HASIL}

\section{Kunci identifikasi lalat buah}

1a Tergum menyatu, pinggang menggenting, toraks berwarna merah hingga cokelat (Gambar 1a).....

..Genus Dacus (Callantra) longicornis

1b Abdomen membulat, pinggang tidak menggenting, tergum terpisah, toraks berwarna beragam (Gambar 1b) Genus Bactrocera 2

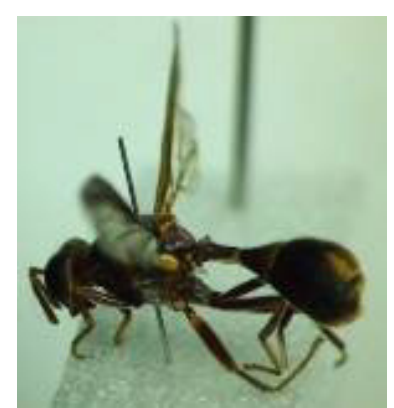

(a)

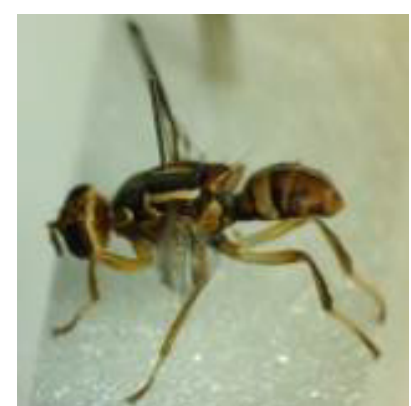

(b)

Gambar 1. Perbedaan abdomen. a: Dacus spp.; b: Bactrocera spp.

2a Tidak memiliki ceromae, terdapat karakter bulla pada serangga jantan (Gambar 2a)

Genus Bactrocera (Bulladacus) mcgregori

2b Memiliki ceromae, tidak terdapat karakter bulla pada serangga jantan (Gambar 2b) 3

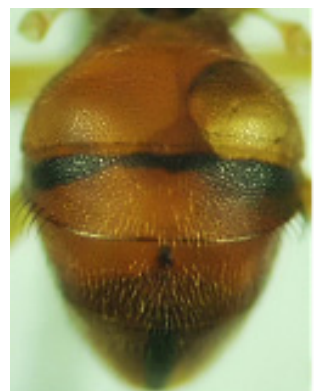

(a)

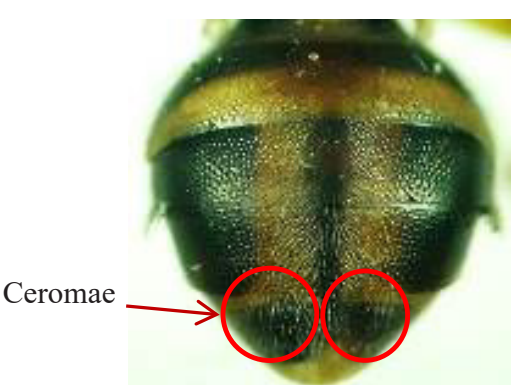

(b)

Gambar 2. Keberadaam ceromae pada abdomen a: tidak terdapat pada subgenus Bulladacus; b: terdapat pada subgenus Bactrocera.

3a Terdapat medial postsutural vittae pada skutum, umumnya tertarik atraktan cue lure (Gambar 3a) ..... 4

3b Tidak terdapat medial postsutural vittae pada skutum, umumnya tertarik atraktan methyl engenol lure (Gambar 3b) 7

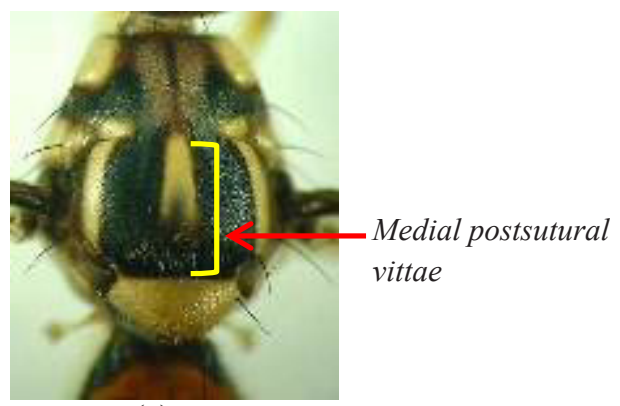

(a)

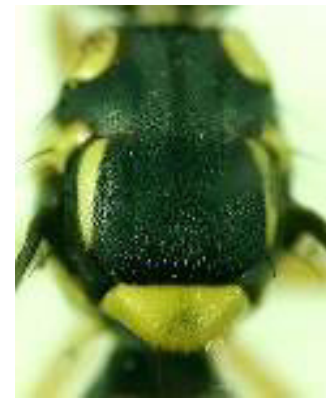

(b)

Gambar 3. Karakter medial postsutural vittae pada toraks a: toraks dengan medial postsutural vittae; b: tidak terdapat medial postsutural vittae pada toraks. 
4a Terdapat pita kostal dan cubital streak dan tidak terdapat pita tambahan pada sayap (Gambar 4a) ....... 5 4b Terdapat pita kostal dan cubital streak serta terdapat pita tambahan pada sayap (Gambar 4b) .......... 6

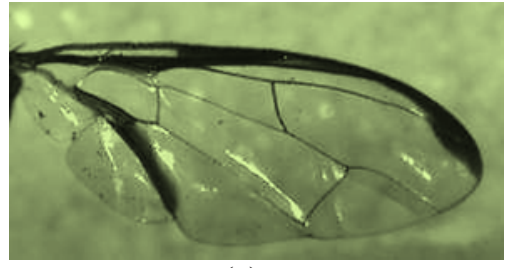

(a)

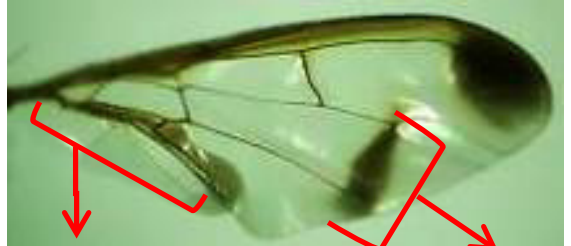

(b)

Pita tambahan

Gambar 4. Karakter sayap. a: sayap tanpa pita tambahan; b: sayap dengan karakter pita tambahan.

5a Tidak terdapat spot pada ujung sayap (Gambar 5a) Bactrocera (Zeugodacus) vulta $5 b$ Terdapat spot pada ujung sayap (Gambar 5b) 15

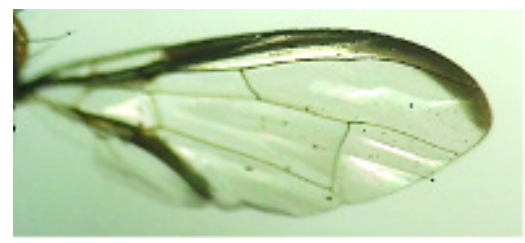

(a)

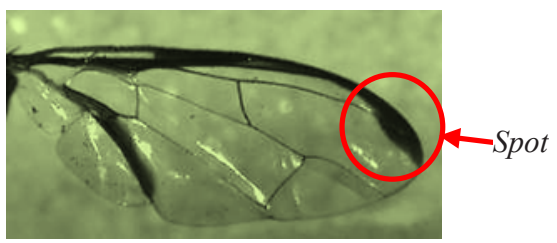

(b)

Gambar 5. Karakter spot pada sayap. a: sayap tanpa spot; dan b: sayap dengan spot pada bagian ujung.

6a Toraks berwarna cokelat (Gambar 6a) Bactrocera (Bactrocera) cucurbitae 6b Toraks berwarna hitam (Gambar 6b) Bactrocera (Zeugodacus) calumniata

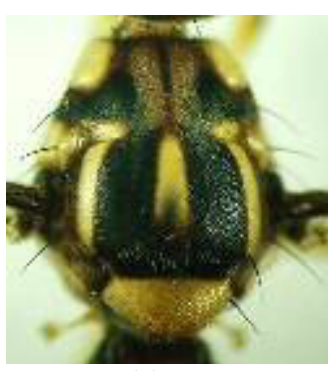

(a)

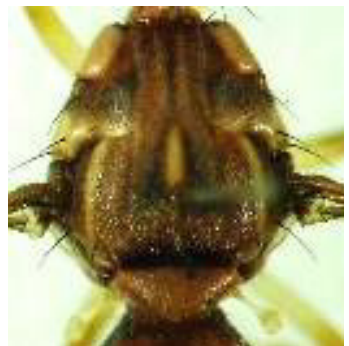

(b)

Gambar 6. Warna toraks. a: hitam; b: coklat.

7a Tidak terdapat pita melintang dari batas kostal hingga bagian bawah sayap (Gambar 7a) 9

$7 \mathrm{~b}$ Terdapat pita melintang dari batas kostal hingga bagian bawah sayap lebih dari 1 pita (Gambar 7b).... 8

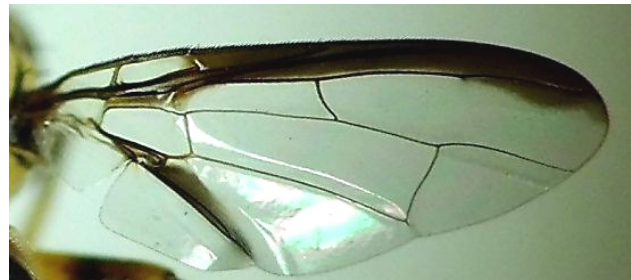

(a)

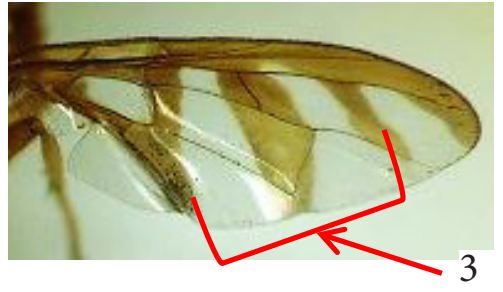

(b)

Gambar 7. Karakter pita melintang pada sayap. a: tanpa pita melintang; b: dengan pita melintang. 
8a Jumlah pita melintang dari batas kostal hingga bagian bawah sayap terdiri dari 2 pita (Gambar 8a) ..... Bactrocera (Bactrocera) albistrigata

8b Jumlah pita melintang dari batas kostal hingga bagian bawah sayap terdiri dari 3 pita (Gambar 8b) ..

..Bactrocera (Bactrocera) umbrosa

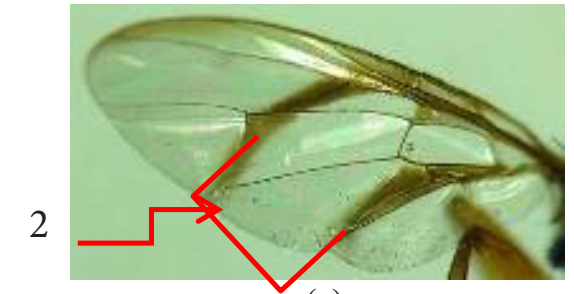

(a)

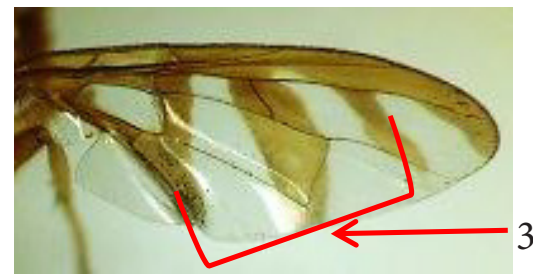

(b)

Gambar 8. Jumlah pita melintang pada sayap. a: 2 pita melintang; b: 3 pita melintang.

9a Skutum cokelat, merupakan spesies besar(Gambar 9a)

Bactrocera (Bactrocera) moluccensis

9b Skutum hitam, merupakan spesies kecil (Gambar 9b)

10a Tidak terdapat pola "T" pada tergum abdomen, terdapat spot pada ujung sayap (Gambar 9a)

Bactrocera (Bactrocera) latifrons

10b Terdapat pola "T" pada tergum abdomen. Tidak terdapat spot pada ujung sayap (Gambar 9b) ...... 11

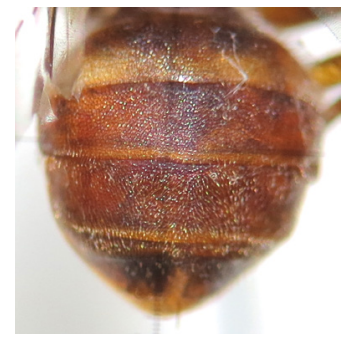

(a)

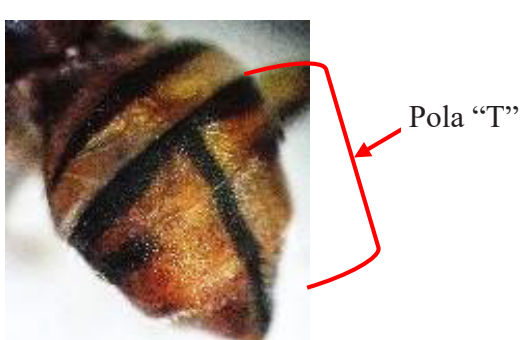

(b)

Gambar 9. Pola T pada abdomen. a: tanpa pola T; b: dengan pola T.

11a Lateral postsutural vittae berukuran sempit(Gambar 10a)......Bactrocera (Bactrocera) verbascifoliae 11b Lateral postsutural vittae berukuran medium hingga lebar (Gambar 10b) 12

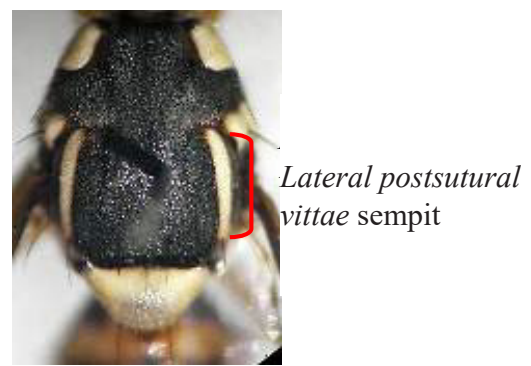

(a)

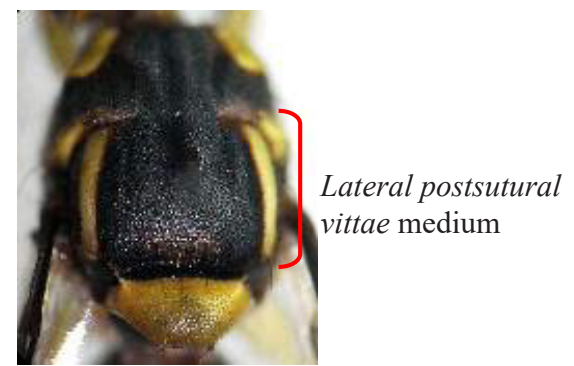

(b)

Gambar 10. Lebar lateral postsutural vittae pada toraks. a: sempit; b: medium.

12a Pita kostal konfluen dan overlapping terhadap R2+3 (Gambar 11a) 3

12b Pita kostal konfluen dan overlapping terhadap R4+5 (Gambar 11b) 


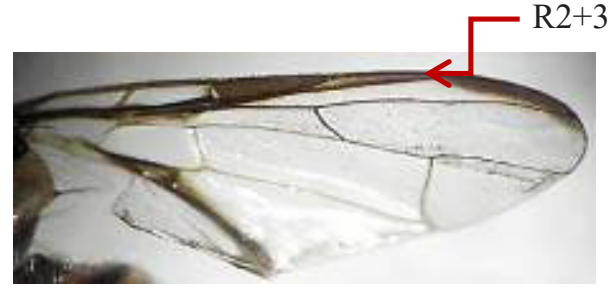

(a)

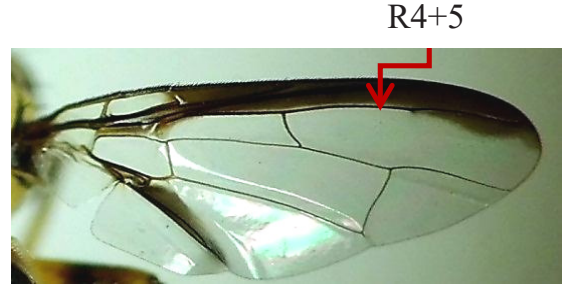

(b)

Gambar 11. Lebar pita kostal. a: pita kostal konfluen (sejajar) dan overlapping (tumpang tindih) terhadap venasi R2+3; b: pita kostal konfluen dan overlapping terhadap venasi R4+5.

13a Lateral postsutural vittae bertipe paralel atau subparalel (Gambar 12a) 16

13b Lateral postsutural vittae berbentuk meruncing (Gambar 12b) 14

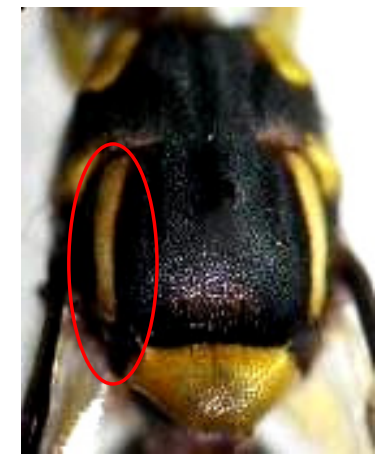

(a)

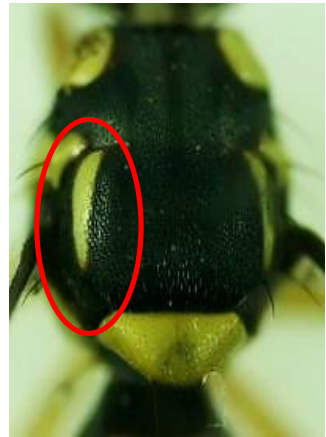

(b)

Gambar 12. Tipe lateral postsutural vittae. a: paralel; b: meruncing.

14a Lateral postsutural vittae pendek, jarak antara ujung lateral postsutural vittae dan seta intra alar lebar (Gambar 13a)

Bactrocera (Bactrocera) usitata

14b Lateral postsutural vittae memanjang, jarak antara ujung lateral postsutural vittae dan seta intra alar pendek (Gambar 13b) Bactrocera (Bactrocera) melastomatos

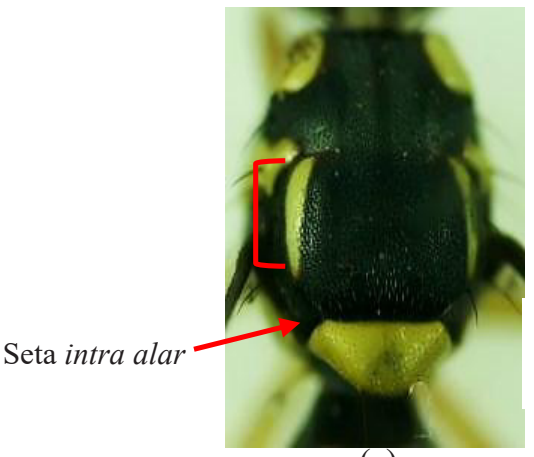

(a)

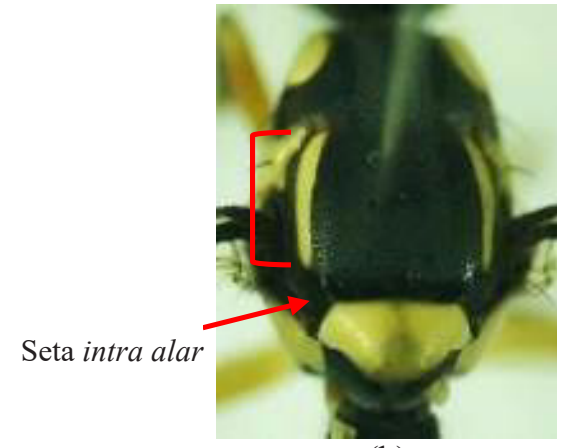

(b)

Gambar 13. Jarak antara lateral postsutural vittae dan seta intra alar. a: pendek; b: panjang.

15a Terdapat garis hitam pada bagian wajah (di bagian atas mulut) (Gambar 14a).

Bactrocera (Bactrocera) caudata

15b Terdapat spot bulat hitam pada bagian wajah (Gambar 14b) Bactrocera (Bactrocera) tau 


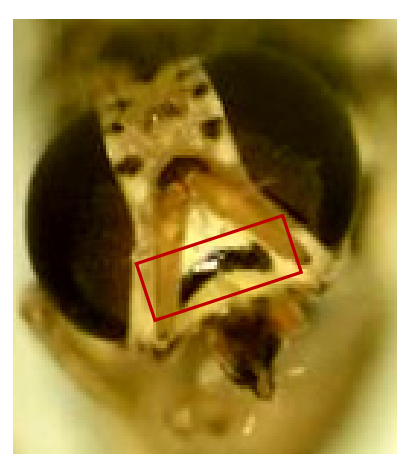

(a)

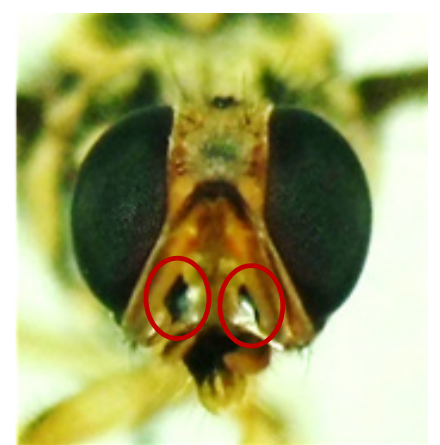

(b)

Gambar 14. Bentuk spot pada bagian atas alat mulut. a: garis; b: bulat.

16a Pita kostal overlapping terhadap $\mathrm{R} 2+3$ dengan lebar yang sama hingga melewati ujung $\mathrm{R} 2+3$ (Gambar 15a)

16b Pita kostal konfluen terhadap $\mathrm{R} 2+3$ dan tidak memanjang sepanjang ujung sayap (Gambar $15 b)$

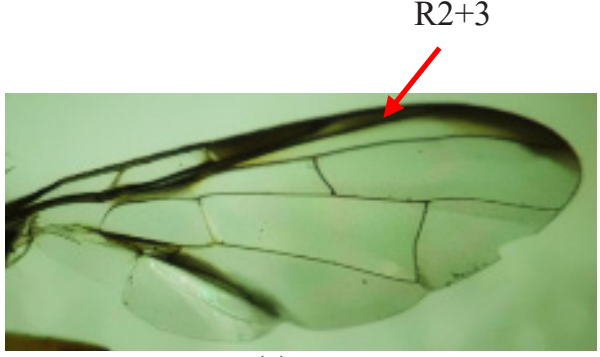

(a)

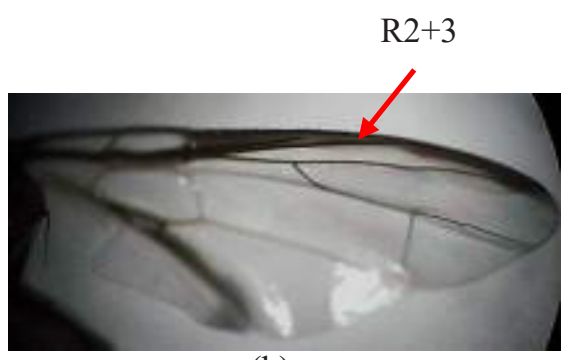

(b)

Gambar 15. Posisi pita kostal terhadap R2+3. a: overlapping; b: konfluen.

17a Terga abdomen III dan IV dengan bagian gelap pada lateral yang melebar, spesies kecil dengan panjang kira-kira 5,2 $\mathrm{mm}$ (Gambar 16a)

Bactrocera (Bactrocera) verbascifoliae

17b Terga abdomen III dan IV dengan bagian gelap pada lateral yang menyempit, spesies besar dengan panjang kira-kira 6,2-6,4 mm (Gambar 16b)

Bactrocera (Bactrocera) papayae

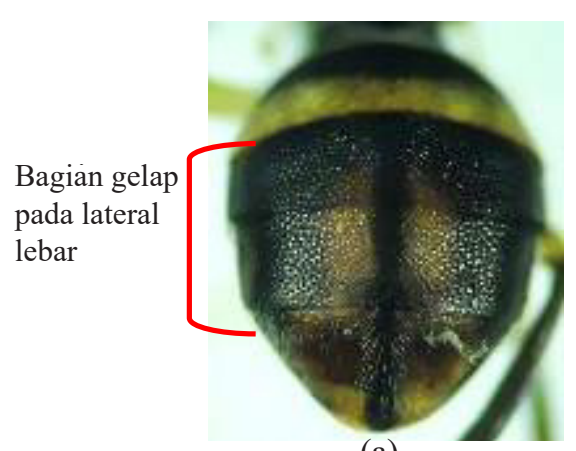

(a)

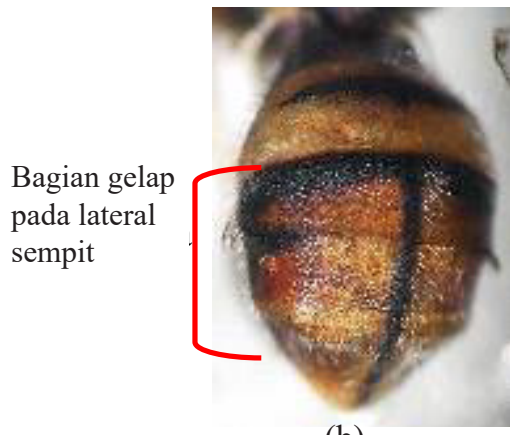

(b)

Gambar 16. Bagian gelap pada lateral abdomen. a: melebar; b: menyempit.

18a Terga abdomen III-IV dengan bagian gelap pada medial yang melebar, ujung pita lateral pada abdomen berbentuk persegi (Gambar 17a)

$18 \mathrm{~b}$ Terga abdomen III-IV dengan bagian gelap pada lateral yang menyempit, ujung pita lateral pada abdomen berbentuk segitiga (Gambar 17b) 


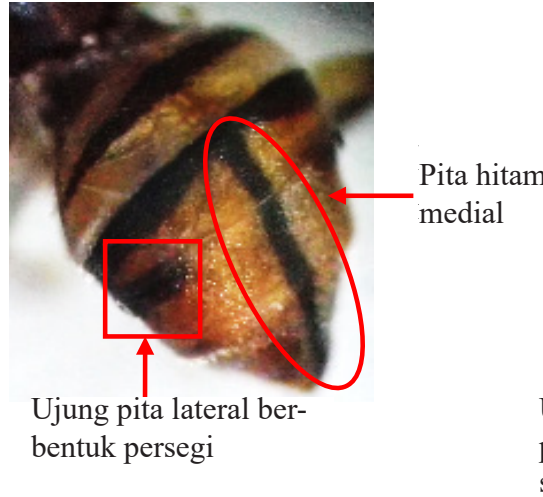

(a)

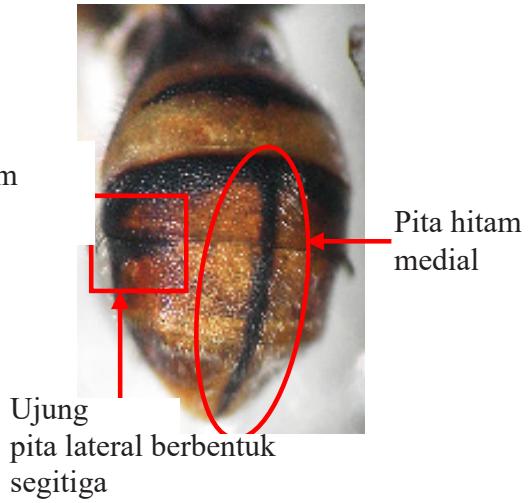

(b)

Gambar 17. Pita medial pada abdomen. a: melebar; b: menyempit.

19a Pita kostal memanjang dan menyempit pada ujung sayap (Gambar 18a)

Bactrocera (Bactrocera) carambolae

19b Pita kostal memanjang dan tetap lebar hingga ujung sayap (Gambar 18b)

Bactrocera (Bactrocera) occipitalis

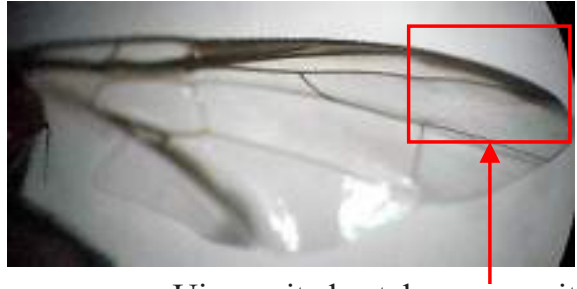

Ujung pita kostal menyempit

(a)

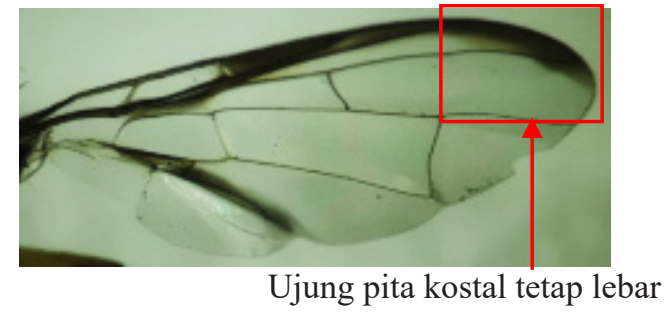

(b)

Gambar 18. Pita kostal pada ujung sayap. a: menyempit; b: melebar.

\section{PEMBAHASAN}

Kunci identifikasi ini disusun sebagai media untuk mempermudah dalam melakukan identifikasi spesies lalat buah di area Bogor dan beberapa daerah di sekitarnya. Selain itu, adanya informasi terkait sebaran atau distribusi spesies lalat buah dapat bermanfaat dalam proses perbandingan hasil monitoring lalat buah yang dilakukan di area ini. Identifikasi merupakan bagian dari kegiatan monitoring lalat buah yang kemudian berkaitan dengan pengendalian lalat buah (Sarwar 2015).

Dari 18 spesies lalat buah yang ditemukan dan digunakan dalam penyusunan kunci identifikasi ini, terdapat beberapa spesies yang umum ditemukan di berbagai area tropis, seperti B. umbrosa, $B$. carambolae, B. papayae yang juga dapat diperoleh dari rearing berbagai buah dan sayuran. Berdasarkan hasil monitoring dan survei lalat buah yang pernah dilakukan sebelumnya oleh Australia (AQIS 2008), menunjukkan bahwa ditemukan 17 spesies yang juga ditemukan pada penelitian ini. Bactrocera (Bulladacus) mcgregori merupakan spesies lalat buah yang tidak ditemukan pada survei sebelumnya. Spesies ini merupakan monofag yang hanya ditemukan pada tanaman melinjo. Pada beberapa teknik identifikasi, terkadang informasi inang dapat digunakan dalam proses identifikasi. 
Bactrocera (Bactrocera) albistrigata de meijere

Dacus albistrigatus Meijere, 1911

Bactrocera (Bactrocera) albistrigata Norrbom et al., 1998

Persebaran. tersebar sepanjang Asia Tenggara

Karakter. postpronotal lobes kuning, lateral postsutural vittae dengan lebar medium yang memanjang dan berakhir sebelum seta intra alar. Costal band tumpang tindih R2+3, garis mesopleural tidak mencapai postpronotal lobes. Pola warna pada sayap terdiri dari 1 pita yang melintang dari pita kostal menuju garis bagian bawah sayap.

\section{Bactrocera (Bulladacus) mcgregori Bezzi}

Chaetodacus mcgregori Bezzi, 1919

Dacus (Strumeta) mcgregori Hardy \& Adachi, 1954

Persebaran. Asia Tenggara (Filipina)

Karakter. Spesies kecil, wajah fulvous, postpronotal lobes dan notopleura kuning, skutum merahkecoklatan dengan tanda gelap, terdapat lateral postsutural yellow vittae, tidak terdapat medial postsutural yellow vittae, tidak memiliki ceromae, terdapat karakter bulla pada serangga jantan.

\section{Bactrocera (Zeugodacus) vulta Hardy}

Bactrocera (Zeugodacus) vulta Hardy, 1985

Persebaran. Asia Tenggara

Karakter. Spesies ini berukuran medium. Wajah berwarna kuning pucat disertai dengan adanya spot oval hitam berukuran besar. Skutum berwarna hitam, sedangkan skutelum dan postpronotal lobes berwarna kuning. Lateral postsutural vittae bertipe paralel dan subparalel. Terdapat medial postsutural vittae pada toraks. Pita kostal pada sayap sejajar dengan R4+5. Cubital streak berwarna gelap dan lebar.

\section{Bactrocera (Bactrocera) cucurbitae Coquillett}

Dacus cucurbitae Coquillett, 1899

Bactrocera cucurbitae Bezzi, 1913

Chaetodacus cucurbitae Bezzi, 1916

Strumeta cucurbitae Perkins, 1938

Dacus (Strumeta) cucurbitae Hardy \& Adachi, 1954

Dacus (Zeugodacus) cucurbitae Drew, 1989

Dacus yuiliensis Tseng \& Chu, 1992

Persebaran. Thailand, Indonesia (Jawa)

Karakter. Lebar pita kostal seragam, pita kostal sejajar dengan pita R2+3, terdapat 4 seta skutelar, terdapat lateral postsutural yellow vittae, sayap memiliki warna yang minim (kecuali pada pita kostal dan cubital streak).

\section{Bactrocera (Zeugodacus) calumniata Hardy}

Dacus calumniata Hardy, 1970

Bactrocera (Zeugodacus) calumniata Norrborn et al., 1998

Persebaran. Filipina, Indonesia (Bali, Jawa, Sumatera)

Karakter. Terdapat lateral postsutural vittae dengan tipe paralel dan medial postsutural vittae. Sel bc dan c tidak berwarna, skutum berwarna hitam, terdapat 4 seta skutelar, skutelum dan postpronotal lobes berwarna kuning. Pita kostal pada sayap melewati R2+3 dan melebar pada ujung R4+5. Cubital streak lebar dan berwana gelap.

\section{Bactrocera (Bactrocera) umbrosa Fabricius}

Dacus umbrosus Fabricius, 1805

Dacus fascipennis Wiedemann, 1819

Bactrocera fasciatipennis Doleschall, 1856

Dacus conformis Walker, 1856 
Dacus diffusus Walker, 1860

Dacus frenchi Froggatt, 1909

Dacus (Bactrocera) umbrosus-Malloch, 1939

Strumeta umbrosa Perkins, 1939

Strumeta frenchi Perkins, 1939

Dacus (Strumeta) umbrosus Hardy \& Adachi,1954

Bactrocera (Bactrocera) umbrosa Drew, 1989

Bactrocera (Bactrocera) lacerata White \& Evenhuis, 1999

Persebaran. Sepanjang Asia Tenggara, wilayah Pasifik Selatan hingga Caledonia baru

Karakter. Memiliki wajah berwarna kuning pucat dengan sepasang spot oval berukuran medium. Skutum berwarna hitam, sedangkan skutelum dan postpronotal lobes berwarna kuning. Terdapat lateral postsutural vittae dengan tipe paralel dan medial postsutural vittae. Pita kostal pada sayap melewati R2+3 dan melebar pada ujung R4+5. Cubital streak lebar dan berwana gelap. Terdapat pita gelap yang melintang pada dm-cu.

\section{Bactrocera (Bactrocera) moluccensis Perkins}

Strumeta moluccensis Perkins, 1939

Dacus (Strumeta) moluccensis Hardy, 1970

Bactrocera (Bactrocera) moluccensis Drew, 1989

Persebaran. Papua Nugini, serta beberapa pulau, seperti pulau Buru, Indonesia (Jawa, Maluku, Sulawesi, Papua Barat)

Karakter. Wajah berwarna kuning pucat disertai dengan adanya sepasang spot oval berukuran medium. Skutum berwarna merah-cokelat dengan spot berwarna kuning pucat diantara postpronotal lobe dan notopleura. Terdapat garis sempit berwarna kuning pucat yang melintang secara lateral dan medial. Lateral postsutural vittae lebar yang bertipe paralel atau subparalel yang memanjang hingga seta intra alar. Skutelum berwarna kuning.

\section{Bactrocera (Bactrocera) latifrons White \& Liquido}

Chaetodacus latifrons Hendel, 1915

Dacus amoyensis Froggatt, 1909

Dacus parvulus Hendel, 1912

Chaetodacus antennalis Shiraki, 1933

Bactrocera (Bactrocera) latifrons White \& Liquido, 1995

Persebaran. Asia Tenggara

Karakter. Spesies ini memiliki wajah berwarna kuning pucat, disertai dengan adanya sepasang spot bulat hitam berukuran medium. Skutum didominasi oleh warna hitam. Terdapat lateral postsutural vittae dengan tipe paralel yang memanjang menyentuh seta intra alar. Skutelum berwarna kuning. Pita kostal pada sayap melewati atau sejajar terhadap $\mathrm{R} 2+3$. Terdapat spot pada ujung sayap.

\section{Bactrocera (Bactrocera) verbascifoliae Drew \& Hancock}

Bactrocera (Bactrocera) verbascifoliae Drew \& Hancock, 1994

Persebaran. Asia Tenggara

Karakter. Wajah berwarna kuning pucat disertai dengan adanya sepasang spot hitam dengan ukuran medium. Skutum didominasi oleh warna hitam, sedangkan skutelum dan postpronotal lobes berwarna kuning. Terdapat lateral postsutural vittae dengan tipe paralel dan sempit yang memanjang hingga seta intra alar. Pita kostal pada sayap melewati R2+3, terkadang sejajar dengan R2+3.

\section{Bactrocera (Bactrocera) limbifera Bezzi}

Chaetodacus ferrugineus var. limbifera Bezzi, 1919

Strumeta pedestris var. limbifera Perkins, 1938

Dacus (Strumeta) limbiferus Hardy \& Adachi, 1954

Dacus (Strumeta) limbifer Hardy, 1974

Bactrocera (Bactrocera) limbifera Norrbom et al., 1998 
Persebaran. Asia Tenggara

Karakter. Spesies ini merupakan spesies lalat buah yang memiliki ukuran besar. Wajah berwarna kuning pucat disertai dengan adanya sepasang spot oval hitam yang berukuran medium. Warna skutum didominasi oleh warna hitam. Postpronotal lobes berwarna kuning. Terdapat lateral postsutural vittae yang bertipe paralel atau subparalel yang memanjang mencapai seta intra alar. Pita kostal pada sayap berwarna hitam tebal dan lebar hingga sejajar dengan R4+5.

\section{Bactrocera (Bactrocera) usitata Drew \& Hancock}

Bactrocera (Bactrocera) usitata Drew \& Hancock, 1994

Persebaran. Asia Tenggara

Karakter. Wajah berwarna kuning pucat disertai dengan adanya sepasang spot bulat hitam dengan ukuran besar. Skutum berwarna hitam, sedangkan skutelum berwarna kuning. Lateral postsutural vittae bertipe meruncing dan berakhir sebelum seta intra alar. Femur pada tungkai berwarna kuning pucat, dan tibia berwarna lebih gelap. Pita kostal pada sayap melewati R2+3 hampir mendekati R4+5.

\section{Bactrocera (Bactrocera) melastomatos Drew \& Hancock}

Bactrocera (Bactrocera) melastomatos Drew \& Hancock, 1994

Persebaran. Semenanjung Malaysia, Thailand, Singapura, Pulau Andaman, Indonesia (Jawa, Kalimantan, Sumatera).

Karakter. Spesies ini merupakan spesies berukuran besar. Wajah berwarna kuning pucat dengan sepasang spot oval hitam berukuran besar. Skutum didominasi oleh warna hitam dan memiliki postpronotal lobes berwarna kuning. Skutelum berwarna kuning. Lateral postsutural vittae berukuran sempit hingga medium yang memanjang dan berakhir sebelum seta intra alar. Seluruh tibia pada tungkai berwarna gelap dan femur berwarna kuning pucat. Pita kostal pada sayap melewati R2+3 dan memanjang hingga ujung R4+5. Cubital streak sempit dan berwarna kuning pucat.

\section{Bactrocera (Zeugodacus) caudata Fabricius}

Bactrocera (Zeugodacus) caudata Fabricius, 1805

Persebaran. Asia Tenggara

Karakter. Spesies ini merupakan spesies berukuran medium. Wajah berwarna kuning pucat dengan garis hitam pada bagian atas alat mulut postpronotal lobes dan notopleura kuning. Skutum berwarna hitam, sedangkan skutelum berwarna kuning. Lateral postsutural vittae bertipe paralel atau subparalel dan terdapat medial postsutural vittae. Pita kostal pada sayap sejajar terhadap $\mathrm{R} 2+3$ dan melebar pada bagian ujung hingga mencapai R4+5 (menyerupai spot pada ujung sayap).

\section{Bactrocera (Bactrocera) tau Walker}

Bactrocera (Zeugodacus) tau Walker, 1849

Persebaran. Asia Tenggara

Karakter. Spesies ini berukuran medium. Wajah berwarna kuning pucat dengan sepasang spot oval hitam berukuran medium. Skutum berwarna hitam. Lateral postsutural vittae bertipe paralel dengan ukuran medium yang memanjang hingga mencapai seta intra alar. Terdapat medial postsutural vittae pada toraks. Pita kostal pada sayap melewati $\mathrm{R} 2+3$ yang memanjang hingga bertemu pada spot yang terletak di ujung sayap. Cubital streak berwarna gelap yang lebar.

\section{Bactrocera (Bactrocera) papayae Drew \& Hancock}

Bactrocera (Bactrocera) papayae Drew \& Hancock, 1994

Persebaran. Asia Tenggara

Karakter. Spesies ini memiliki warna wajah kuning pucat dengan sepasang spot oval hitam berukuran besar. Terdapat lateral postsutural vittae pada toraks dengan tipe paralel atau sub paralel yang berukuran medium hingga lebar. Lateral postsutural vittae berakhir pada atau melewati seta intra alar. Skutum 
didominasi oleh warna hitam dengan warna cokelat tua pada bagian belakang lateral postsutural vittae. Pita kostal pada sayap dapat terletak sejajar atau melewati $\mathrm{R} 2+3$, sel bc dan c kurang berwarna.

\section{Bactrocera (Bactrocera) carambolae Drew \& Hancock}

Bactrocera (Bactrocera) carambolae Drew \& Hancock, 1994

Persebaran. Asia Tenggara

Karakter. Spesies ini memiliki wajah berwarna kuning pucat serta terdapat sepasang spot oval hitam berukuran medium. Skutum didominasi oleh warna hitam disertai dengan warna cokelat yang terdapat pada bagian belakang lateral postsutural vittae, sekitar mesonotal suture dan di dalam postpronotal lobes. Terdapat lateral postsutural vittae dengan tipe paralel hingga sub paralel berukuran medium hingga lebar. Skutum pada didominasi oleh warna hitam dan warna cokelat pada bagian belakang lateral postsutural vittae. Pita kostal pada sayap overlapping terhadap R2+3.

\section{Bactrocera (Bactrocera) occipitalis Drew \& Hancock}

Bactrocera (Bactrocera) occipitalis Drew \& Hancock, 1994

Persebaran. Asia Tenggara

Karakter. Wajah berwarna kuning pucat disertai dengan adanya sepasang spot oval hitam yang berukuran besar. Skutum didominasi oleh warna hitam postpronotal lobes berwarna kuning. Lateral postsutural vittae bertipe paralel atau sub paralel dengan ukuran medium hingga lebar yang memanjang hingga seta intra alar. Abdomen memiliki transversal black band yang sempit, ujung sudut anterolateral pada terga IV berbentuk persegi. Pita kostal pada sayap melewati R2+3 yang melebar hingga ujung sayap.

\section{Dacus (Callantra) longicornis Wiedemann}

Dacus (Callantra) longicornis Wiedemann, 1830

Persebaran. Asia Tenggara

Karakter. Genus Dacus memiliki karakter morfologi yang spesifik, yaitu terdapat penggentingan pada abdomen dan merupakan genus dengan ukuran tubuh lebih besar dari genus lalat buah lainnya. Wajah berwarna kuning pucat dengan sepasang spot bulat pada wajah dengan ukuran medium. Postpronotal lobe berwarna kuning, notopleura kuning, skutum berwarna cokelat-merah, skutelum berwarna kuning, serta tidak memiliki lateral dan medial postsutural yellow vittae. Terdapat segitiga berwarna kuning yang terletak batas anterior dari mesonotal suture. Pita kostal pada sayap overlapping terhadap R4+5.

\section{KESIMPULAN}

Jumlah spesies lalat buah di Kabupaten Bogor dan area sekitarnya ditemukan sebanyak 18 spesies. Untuk mengetahui spesies lalat buah dapat dilakukan dengan membandingkan beberapa karakter, diantaranya face spot, lateral postsutural vittae, warna tungkai, lebar dan sempitnya pita kostal, medial longitudinal band, serta lateral margin dari terga III hingga V.

\section{UCAPAN TERIMA KASIH}

Terima kasih kepada bapak Dr. Suputa yang telah membantu dalam proses identifikasi lalat buah pada penelitian ini.

\section{DAFTAR PUSTAKA}

[AQIS]Australian Quarantine and Inspection Service. 2008. Fruit Flies Indonesia: Their Identification. Pest Status dan Pest Management. Brisbane: International Center for The Management of Pest Fruit Flies, Griffith University and Ministry of Agriculture, Republic of Indonesia.

[CABI] Center in Agricultural and Biological Institute. 2007. Crop Protection Compendium (CD-ROM) Wallingford: CAB International 2.

Drew R, Romig MC. 2013. Tropical Fruit Flies of South East Asia. Brisbane: Griffith University.

Faria FA, Perre P, Zucchi RA, Jorge LR, Lewinsohn TM, Rocha A, Torres R. 2014. Automatic identification of fruit flies (Diptera: Tephritidae). Journal of Visual Communication and Image Representation 25:1516-1527. doi: http://dx.doi. org/10.1016/j.jvcir.2014.06.014. 
Larasati A. 2012. Keanekaragaman, Persebaran dan Kunci Identifikasi Lalat Buah (Diptera: Tephritidae) di Kabupaten Bogor dan Sekitarnya. Tesis. Bogor: Institut Pertanian Bogor.

Prabhakar CS, Sood P, Mehta PK. 2012. Pictorial key for predominant Bactrocera dan Dacus fruit flies (Diptera: Tephritidae) of North Western Himalaya. Arthropods 1:101-111.

Pusat Teknik dan Metoda Karantina Hewan dan Tumbuhan. 2004. Petunjuk Teknis Surveilan Lalat Buah. Jakarta: Badan Karantina Pertanian.

Sarwar M. 2015. How to manage fruit fly (Family Tephritidae) pest damage on different plant host species by take up of physical control measures. International Journal of Animal Biology 1:124129.
Siwi SS. Hidayat P. Suputa. 2006. Taksonomi dan Bioekologi Lalat Buah Penting di Indonesia (Diptera: Tephritidae). Bogor: Balai Besar Penelitian dan Pengembangan Bioteknologi dan Sumberdaya Genetik Pertanian.

White IM, Harris MME. 1992. Fruit Flies of Economic Significance: Their Identification and Bionomics. Canberra: CAB Publishing. 